\section{Rheumatoid arthritis - non biologic treatment}

\section{AB0417 EFFICACY AND SAFETY OF METHOTREXATE AND LEFLUNOMIDE AS A COMBINATION THERAPY IN RHEUMATOID ARTHRITIS PATIENTS WITH HIGH DISEASE ACTIVITY PRESENTING AT A TERTIARY CARE SETTING IN PAKISTAN}

B. Salim, S. Samreen, A. Nasim, H. Gul, A. Masood. Rheumatology, Rawalpindi, Pakistan

Background: In the management of rheumatoid arthritis (RA), the goal is remission. However it is not easy to attain this goal in all patients. Its not only the high disease activity, but rather other factors like availability and cost of biologics in developing countries. Therefore various combination therapies of conventional DMARDs are in vogue in such scenarios. Methotrexate (MTX) and Leflunomide (LEF) in combination is an effective option which can be fairly utilized in resource constraint settings to induce remission.

Objectives: To study the efficacy and safety profile of MTX+LEF combination in patients with active RA at 24 weeks.

Methods: This is a quasi-experimental study conducted at Rheumatology department, Fauji Foundation Hospital, Rawalpindi. 95 patients with active RA despite optimal dose (20-25 mg/week) of MTX. Leflunomide $20 \mathrm{mg} /$ day was added. Patients underwent clinical and laboratory review at 0, 4, 12 and 24 weeks to note down primary efficacy end points and adverse effects.

Results: Ninety five patients were enrolled with a mean age (years) \pm SD of $51.7 \pm 8.9$ and a mean duration of disease (years) of 8.6 \pm 7.1. Patients had active disease at baseline with a mean disease activity score (DAS28) of $5.99 \pm 0.6$. At 24 weeks the mean change in tender joint count (TJ), swollen joint count (SJ), patients pain score on visual analogue scale (VAS) and DAS 28 were all statistically significant ( $p$-value 0.000 ). The mean change in $m$ HAQ was also statistically significant ( $p$-value 0.000$)$.

At 6 months the most frequent side effects (though mostly mild); were abdominal pain and nausea. 78 patients $(79.1 \%)$ continued with the combination therapy. Only 3 patients stopped the treatment temporarily (due to raised ALT and vomiting). 14 patients discontinued treatment mainly due to diarrhea, severe oral ulcers and markedly raised ALT.

Table 1. Baseline clinical and demographic feature of patients enrolled for MTX+LEF combination therapy

\begin{tabular}{lc}
\hline Total patients & $95(100 \%)$ \\
Age mean \pm SD (years) & $51.7 \pm 8.9$ \\
Gender m/f & $2 / 93$ \\
Duration of diseasemean \pm SD (years) & $8.6 \pm 7.1$ \\
RA factor (positive) & $72(75.8 \%)$ \\
Anti CCP (positive) & $61(64.2 \%)$ \\
Premorbids & \\
$\quad$ Diabetic (DM) & $10(10.5 \%)$ \\
Hypertensive (HTN) & $16(16.2 \%)$ \\
DM+HTN & $3(3.2 \%)$ \\
\hline
\end{tabular}

Table 2. Outcome/efficacy measure of MTX+LEF $(n=95)$

\begin{tabular}{lccc}
\hline & Baseline $(0$ week $)$ & 24 weeks & p-value \\
\hline Mean Tj & $14.92 \pm 6.44$ & $3.38 \pm 2.38$ & 0.000 \\
Mean Sj & $4.29 \pm 2.30$ & $0.90 \pm 1.28$ & 0.000 \\
Mean pain VAS (Patient) & $7.19 \pm 1.86$ & $2.91 \pm 1.85$ & 0.000 \\
Mean ESR & $33.3 \pm 9.10$ & $16.78 \pm 5.99$ & 0.000 \\
Mean DAS 28 & $5.99 \pm 0.64$ & $3.52 \pm 0.86$ & 0.000 \\
Mhaq & $1.75 \pm 0.64$ & $0.59 \pm 0.42$ & 0.000 \\
\hline
\end{tabular}

Conclusions: MTX+LEF combination is an effective and safe option in RA patients failing MTX monotherapy provided regular clinical and laboratory monitoring is done.

Disclosure of Interest: None declared

DOI: 10.1136/annrheumdis-2017-eular.1399

\section{AB0418 COMPARISON OF ANTI-INFLAMMATORY DRUGS WITH GLUCOCORTICOIDS IN TREATMENT OF RHEUMATOID ARTHRITIS}

B.N. Coskun ${ }^{1}$, F. Ulutaş ${ }^{2}$, S. Ermurat ${ }^{1}$, E. Dalkılıc ${ }^{1} .{ }^{1}$ Rheumatology; ${ }^{2}$ Internal Medicine, Uludag University, Bursa, Turkey

Background: Rheumatoid arthritis (RA) is a chronical autoimmune disease that commonly presented with symmetrical polyarthritis of hands and feet. Pharmacological treatment options are non-steroid anti-inflammatory drugs (NSAIDs), glucocorticoids (GK) and disease modifying anti rheumatoid drugs (DMARDs) ([csDMARDs] or [tsDMARDs or [bDMARD]

Objectives: In this study we aimed to review the use of NSAID and GK in our patients.

Methods: The patients who diagnosed as RA at our office were included in the study. Patients were classified with EULAR 2010 RA criteria. The demographics and medications of the patients were recorded. All patients we examined pain with visual analog scale (VAS), global assessment of patient and doctor, number of tender and swollen joints (28 joints), health assessment questionnaire (HAQ),
$\mathrm{C}$ - reactive protein (CRP), eritrocyte sedimentation rate (ESR), rheumatoid factor (RF) and anti - CCP. We assessed activity of disease by using disease activity score DAS28.

Results: A total of 686 patients were enrolled in the study (580 female [84.5\%], 106 male [15.5\%]). Mean age was $53.23 \pm 12.21$ and mean length of diagnosis was $10.74 \pm 7.59$ months. The rate of extra-articular disease was $17.9 \%$ and the deformity rate was $31.3 \%$. In all patients, activity of disease was mild in $55 \%$, moderate in $37.8 \%$ and severe in $7.3 \%$ with regard to DAS28 score. The disease activity was mild in $54.6 \%$, moderate in $43.11 \%$ and severe in $2.3 \%$ in patients who were using only NSAIDS. These rates of diseases activity was $57.2 \%, 40.7 \%$ and $2.1 \%$ in mild, moderate and severe disease respectively for the patients using only GK. In patients using both NSAIDs and GK, the disease activity was mild in $55 \%$, moderate in $44 \%$ and severe in $1 \%$. Comparison of the disease activity with medications revealed statistically significant difference in patients that using only NSAID and using both, but not in that using only steroid (respectively p: 0.022, p: 0.025, p: 0.46)

\begin{tabular}{lccc}
\hline DAS 28 & Mild $<3,2$ & Moderate $\geq 3,2-<5,1$ & Severe $\geq 5,1$ \\
\hline All patients $\%$ & 55 & 37,8 & 7,3 \\
Only NSAIDS $\%$ & 54,6 & 43,11 & 2,3 \\
Only GK \% & 57,2 & 40,7 & 2,1 \\
Both NSAIDs and GK \% & 55 & 44 & 1,0 \\
p & $\mathbf{0 , 0 2 2}$ & $\mathbf{0 , 0 2 5}$ & 0,46 \\
\hline
\end{tabular}

Conclusions: In our study we found that patients has mild activity of disease use highly rates of NSAID and GC. It is important for providing remission using NSAIDs and GC along with DMARD. Our results demonstrate use of both GK and NSAIDS results in better outcomes.

References:

[1] Singh JA, Saag KG, Bridges SL Jr et al. 2015 American College of Rheumatology Guideline for the Treatment of Rheumatoid Arthritis. Arthritis Rheumatol. 2016 Jan;68(1):1-26.

[2] Gaujoux-Viala C, Gossec L. When and for how long should glucocorticoids be used in rheumatoid arthritis? International guidelines and recommendations. Ann N Y Acad Sci. 2014 May; 1318:32-40.

Acknowledgements: None.

Disclosure of Interest: None declared

DOI: 10.1136/annrheumdis-2017-eular.5926

\section{AB0419 REAL WORLD USE OF TOFACITINIB IN RHEUMATOID ARTHRITIS: DATA FROM LATIN AMERICA}

E.E. Schneeberger $^{1}$, A. Salas ${ }^{2}$, L.F. Medina ${ }^{3}$, J.B. Zacariaz ${ }^{4}$, R.D. Mantilla ${ }^{5}$, J.C. Sarmiento-Monroy ${ }^{5}$, L.J. Elizondo ${ }^{6}$, B. Garro ${ }^{7}$, H. Madariaga ${ }^{8}$, L. Górriz ${ }^{9}$, R.D.N. Giorgi ${ }^{10}$, M. Pinheiro ${ }^{11}$, D. Ponce de Leon ${ }^{12}$. ${ }^{1}$ Servicio de Reumatología, Instituto de Rehabilitación Psicofísica; ${ }^{2}$ Servicio de Reumatología, HIGA San Martin de la Plata, Buenos Aires, Argentina; ${ }^{3}$ Servicio de Reumatología, Hospital Universitario del Valle, Cali, Colombia; ${ }^{4}$ Servicio de Reumatología, Hospital Italiano, Buenos Aires, Argentina; ${ }^{5}$ Epidemiólogo, Centro de Dermatología y Reumatología FUNINDERMA, Bogotá, Colombia; ${ }^{6}$ Reumatólogo, Centro de Investigación Clínica de Ciudad Obregón, Sonora, Mexico: ${ }^{7}$ Reumatólogo, Centro de Excelencia en Reumatología, Lima; ${ }^{8}$ Reumatólogo, Clínica del Sur, Arequipa, Peru; ${ }^{9}$ Servicio de Reumatología, Hospital Santo Tomas, Panamá, Panama; ${ }^{10}$ Servicio de Reumatología, Hospital do Servidor Público Estadual; ${ }^{11}$ Pfizer Inc, São Paulo, Brazil; ${ }^{12}$ Pfizer Inc, Lima, Peru

Background: Tofacitinib is an oral JAK inhibitor for the treatment of RA. Tofacitinib can be given as monotherapy or with csDMARDs. Published data on real world (RW) tofacitinib use in Latin America (LA) are limited. We characterise the patient (pt) population starting tofacitinib and gain insights into the safety profile in the RW LA setting.

Methods: Initial tofacitinib therapies in adult RA pts from 10 private/public centres in 6 countries (Argentina, Brazil, Colombia, México, Panamá, Perú) were considered. Data were retrospectively obtained via a standardised format, focusing on demographics, drug history, adverse events (AEs), safety events of special interest, latent tuberculosis (TB) screening, selected confirmed laboratory abnormalities and discontinuation rates. Tofacitinib use as monotherapy or with csDMARDs was at the rheumatologist's discretion.

Results: 288 pts with severe active RA were included; most were female ( $n=263$; $91 \%$ ), mean (SD) age was 51.3 (6.36) years (yrs) and mean (SD) disease duration was 10.4 (4.0) yrs. $89 \%$ of pts were RF+ or ACPA+. The max (range) follow-up period was $22(10-34)$ months. Tofacitinib was given as 2 nd-line therapy (post-csDMARD) in 44\% of pts, after one biologic DMARD (bDMARD) in $18 \%$ of pts and after $\geq 2$ bDMARDs in $38 \%$ of pts. Tofacitinib was given as monotherapy in $117 / 283(41 \%)$ pts and with csDMARDs in $171 / 283(59 \%)$ pts. Tofacitinib usage corresponds to $13 \%$ of advanced therapies (JAK inhibitors, bDMARDs and biosimilars). Thirty-eight AEs were observed; upper respiratory infections $(n=11)$, skin infection $(n=5)$, herpes zoster $(H Z ; n=4)$ and urinary infections $(n=4)$ were most common. Gastrointestinal intolerance was seen in 2 pts. Three (1\%) pts had serious infection events (SIEs); no opportunistic infections (Ols), including TB, occurred. All HZ cases ( $n=4 ; 1.4 \%$ ) were monomeric, non-serious and resolved without complication after antiviral therapy. Before starting tofacitinib, 5 pts $(1.7 \%)$ were vaccinated against $\mathrm{HZ}$ and $5.6 \%$ were diagnosed with latent TB. No active 
TB cases occurred with tofacitinib treatment. One malignancy (thyroid cancer) was reported. Severe ( $>3$ ULN) elevation of liver enzymes or increases of CPK above normal were infrequent $(<1 \%)$; no severe cytopenias were reported. Lipid increases occurred in $10 \%$ of pts. Tofacitinib was withdrawn in 40 pts $(13.9 \%)$ due to lack of efficacy $(n=20 ; 7 \%)$, AEs $(n=11 ; 3.8 \%)$ or other reasons $(n=9 ; 3.1 \%)$, such as loss of follow-up, pregnancy, access issues or travel. Limitations include limited pt numbers and follow-up of exposure.

Conclusions: In the RW LA setting, tofacitinib was used mostly as 2nd-line therapy; no new safety signals emerged vs clinical trials. SIEs and HZ were uncommon; no cases of TB/other Ols occurred, but were seen in the clinical program.

Acknowledgements: This study was sponsored by Pfizer Inc. Editorial support was provided by $\mathrm{K}$ Irving of $\mathrm{CMC}$ and funded by Pfizer Inc.

Disclosure of Interest: E. Schneeberger: None declared, A. Salas Speakers bureau: AbbVie, Pfizer Inc, L. F. Medina: None declared, J. B. Zacariaz: None declared, R. D. Mantilla Grant/research support from: Abbott, AbbVie, Biopas, Bristol-Myers Squibb, Novartis, Pfizer Inc, Roche, Consultant for: Abbott, AbbVie, Biopas, Bristol-Myers Squibb, Novartis, Pfizer Inc, Roche, Speakers bureau: Abbott, AbbVie, Biopas, Bristol-Myers Squibb, Novartis, Pfizer Inc, Roche, J. C. Sarmiento-Monroy: None declared, L. J. Elizondo Grant/research support from: Amgen, Roche, Consultant for: Instituto Mexicano del Seguro Social, B. Garro: None declared, H. Madariaga: None declared, L. Górriz: None declared, R. D. N. Giorgi: None declared, M. Pinheiro Shareholder of: Pfizer Inc, Employee of: Pfizer Inc, D. Ponce de Leon Shareholder of: Pfizer Inc, Employee of: Pfizer Inc DOI: 10.1136/annrheumdis-2017-eular.1607

\section{AB0420 THE SAME TREATMENT RESPONSE OF MONO- AND COMBINED-MTX TREATMENT IN DMARDS-NAIIVE TURKISH PATIENTS WITH SEROPOSITIVE RHEUMATOID ARTHRITIS AND THE IMPORTANCE OF PULMONARY TOXICITY}

F.F. Ayhan ${ }^{1,2}$, A. Gümüştepe ${ }^{1}$, B. Nacır ${ }^{1}$, A. Karagöz ${ }^{1} .{ }^{1}$ Physical medicine \& rehabilitation, Ankara Training and Research Hospital, Ankara; ${ }^{2}$ Physical therapy \& rehabilitation, Uşak University, School of Health Sciences, Uşak, Turkey

Background: Methotrexate (MTX) is the anchor drug for the treatment of rheumatoid arthritis (RA). There are important guidelines suggesting mono-MTX treatment at first for pharmacologic treatment of RA $(1,2)$. We thought that these recommendations should be evaluated in different geographic regions and ethnic groups because of genetic factors.

Objectives: Therefore, we aimed to compare the efficacy and adverse effect profile of mono-MTX and combined-MTX treatments in patients with DMARDsnaïve Turkish patients with seropositive RA.

Methods: Hundred patients with seropositive RA (mean age: $47.4 \pm 12.0$ years, 63 females and 37 males) were included. Patients were excluded the past history of using for synthetic or biologic DMARDs or moderate-high dose steroid (>10mg/day), viral hepatitis, transaminase elevations, and other contra-indications for MTX. Then they were divided as mono-MTX $(n=57)$ and combined-MTX $(n=43)$ groups.

Results: There was no difference between groups in age $(p=0.34)$, sex $(p=0.104)$, age of onset $(p=0.10)$, MTX-weekly dose $(p=0.228)$, the score of DAS28 $(p=0.783), R F$ level $(p=0.473)$, and CCP level $(p=0.592)$ at the beginning. Patients of combined-DMARDs group used higher dose of prednisolone than patients of mono-MTX group $(p=0.011)$. The change of DAS28 scores was not different between groups. CRP levels of combined-MTX group were higher than mono-MTX group both beginning and at 6th month. The frequencies of adverse events were not different between groups. Gl adverse events are the first line in both groups (28\% vs. $16.3 \%$ ). The frequencies of dose decrease $(7 \%$ vs. $14 \%)$ or stop $(7 \%$ vs. $4.7 \%)$ for MTX were also not different between groups ( $p=0.288, p=0.257$ ). The frequencies of other adverse effects were less than $5 \%$. MTX dose decrease or stop have been moderately correlated with pulmonary involvement $(r=0.4$, $\mathrm{p}=0.02$ ).

Conclusions: Both mono-MTX and combined-MTX treatment had similar efficacy and safety profile in Turkish patients with seropositive RA as reported in studies of other countries suggesting no any advantage of combined MTX compared to mono-MTX (3). The frequency of MTX-stopping in our study was similar to this systematic review $(9 \%)$. As a conclusion, MTX should also be the first choice of the treatment of RA in our country. Pulmonary adverse events should not be ignored.

References:

[1] Singh JA, Saag KG, Bridges SL J, et al. 2015 American College of Rheumatology Guideline for the Treatment of Rheumatoid Arthritis. Arthritis Rheumatol. 2016;68(1):1-26.

[2] Smolen JS, Landewé R, Breedveld FC, et al. EULAR recommendations for the management of rheumatoid arthritis with synthetic and biological diseasemodifying antirheumatic drugs: 2013 update. Ann Rheum Dis. 2014;73(3):492509

[3] Katchamart W, Trudeau J, Phumethum V, et al. Methotrexate monotherapy versus methotrexate combination therapy with non-biologic disease modifying anti-theumatic drugs for RA. Cochrane Database od Systematic Reviews 2010; Issue 4.Art.No.:CD008495.

Disclosure of Interest: None declared

DOI: 10.1136/annrheumdis-2017-eular.2147

\section{AB0421 RAPAMYCIN REDUCES DISEASE ACTIVITY THROUGH RESTORING REGULATORY T CELL NUMBERS IN PATIENTS WITH ACTIVE REFRACTORY RHEUMATOID ARTHRITIS}

H. Niu ${ }^{1}$, Z. Li ${ }^{1}$, J. He ${ }^{1}$, R. Jia ${ }^{1}$, J. Luo ${ }^{1}$, C. Gao ${ }^{2}$, C. Wang ${ }^{1}$, X. Li ${ }^{1}$ ${ }^{1}$ Department of Rheumatology, the Second Hospital of Shanxi Medical University, Taiyuan, China; ${ }^{2}$ Department of Pathology, Brigham and Women's Hospital, Harvard Medical School, Boston, United States

Background: $\mathrm{CD} 4^{+} \mathrm{CD} 25^{+} \mathrm{Foxp}^{+} \mathrm{T}$ regulatory (Treg) cells play a key role in peripheral tolerance. Rapamycin was approved by the FDA to preserve renal allografts and to be efficacious in patients with several autoimmune diseases [1]. Objectives: To investigate the status of Treg cells in active refractory rheumatoid arthritis (RA) and the effects of rapamycin on patients with RA.

Methods: Forty-five active refractory RA patients were enrolled. Rapamycin was used at a dose of $0.5 \mathrm{mg}$ every 2 days [the preliminary, open-label clinical trial of rapamycin (Clinical Trials.gov number: ChiCTR-IPR-17010307)]. Clinical improvement and immunological assessments were performed before 1st rapamycin dose and 12 weeks post treatment. Blood samples were obtained from RA patients and 75 healthy volunteers for estimation of $\mathrm{CD}^{+} \mathrm{T}$ cell subsets.

Results: Two patients dropped out due to non-compliance. As compared to healthy controls (median of Treg cells: $33.32 \mathrm{cell} / \mathrm{ul}$ ), the absolute counts of circulating Treg cells were significantly decreased in patients with active refractory RA (median: $27.17 \mathrm{cell} / \mathrm{ul} ; P=0.046$ ). While the median ratios of Th17/Treg cells in patients with active refractory RA (median: 0.26 ) were significantly higher than those of healthy volunteers (median: $0.19 ; P=0.029$ ). No difference in the absolute counts of circulating Th17 cells and Th1 cells was observed between patients with active refractory RA and healthy subjects. Rapamycin treatment led to clinical improvement with the median post-treatment DAS28-ESR decreasing when compared to baseline (from 4.19 to 3.78 ) in active refractory RA patients. Sixteen patients (16/43 patients, 37.21\%) achieved an EULAR moderate response and 6 patients (6/43 patients, $13.95 \%)$ reached good response at week 12 . Rapamycin administration resulted in an increase in the absolute counts of Treg cells in active refractory RA patients, from a median of $27.17 \mathrm{cell} / \mathrm{ul}$ (at week 0 ) to 37.57 cell/ul (at week 12) $(P=0.041)$. The ratios of Th17/Treg cells shows a reduction from a median of 0.26 at baseline to 0.20 at week 12 , but the difference is not significant $(P=0.376)$. No significant difference was observed in the absolute counts of circulating Th17 and Th1 cells after rapamycin treatment. Interestingly, we observed that Treg cells increased before the complete remission of the disease (DAS28 score $<2.6$ ) in patients with active refractory RA. At week 12, the mean dose of prednisone which refractory RA patients were receiving decreased from $11.98 \mathrm{mg} / \mathrm{d}$ to $8.31 \mathrm{mg} / \mathrm{d}$, with a dose reduced by $>30 \%$ than that at baseline. The categories of DMARDs use were also reduced $(P<0.05)$. No serious adverse events was observed during the 12-week period of rapamycin treatment.

Conclusions: Reduced absolute number of Treg cells was found in the patients with active refractory RA, indicating an imbalance between Th17 and Treg cells. Rapamycin elicits rapid improvement of disease activity via restoring circulating Treg cells numbers in patients with active refractory RA.

References:

[1] Perl A. Activation of mTOR (mechanistic target of rapamycin) in rheumatic diseases. Nat Rev Rheumatol. 2016. 12(3): 169-82.

Disclosure of Interest: None declared

DOI: 10.1136/annrheumdis-2017-eular.270

\section{AB0422 1,25-DIHYDROXYVITAMIN D3 MODULATES T CELLS DIFFERENTIATION AND IMPACTS ON THE PRODUCTION OF ASSOCIATED-CYTOKINES FROM CHINESE HAN PATIENTS WITH EARLY RHEUMATOID ARTHRITIS}

H. Wen ${ }^{1}, \mathrm{X} . \mathrm{Li}^{2} .{ }^{1}$ Rheumatology; ${ }^{2}$ the Second Hospital of Shanxi Medical University, Taiyuan, China

Background: Recent studies have suggested that vitamin D may play a role in select inflammatory diseases including rheumatoid arthritis (RA). Epidemiological studies suggest that there is an association between vitamin $D$ deficiency and susceptibility to RA.

The present study sought to investigate effects of 1,25-dihydroxyvitamin D3 $(1,25(\mathrm{OH}) 2 \mathrm{D} 3)$ on $\mathrm{T}$ cells differentiation and associated cytokines in Chinese Han patients with early rheumatoid arthritis (RA). The results reported that $1,25(\mathrm{OH}) 2 \mathrm{D} 3$ inhibits the synthesis of Th1 cytokines IFN- $\gamma$, Th17 cytokines IL-17, IL-22, IL-6, TNF- $\alpha$, and up-regulates Th2 cytokine IL-4, which indicated that the possible immunoregulatory role and bone-sparing effects of $1,25(\mathrm{OH}) 2 \mathrm{D} 3$ in RA through modulation of the Th1/Th17 and Th2 cytokine balance.

Objectives: To study effects of 1,25-dihydroxyvitamin $\mathrm{D} 3\left(1,25(\mathrm{OH})_{2} \mathrm{D}_{3}\right)$ on $\mathrm{T}$ cells differentiation and associated cytokines in patients with early rheumatoid arthritis (RA).

Methods: The level of Th1, Th2, Th17 and Treg cell were detected with BDFACS Calibur flow cytometer. IFN- $\gamma$, TNF- $\alpha$, IL-2, IL-4, IL-6, IL-10, IL-17 and IL-22 were examined in 54 patients with incipient RA using a cytometric bead array (CBA).

Results: After 72 hours of incubation of peripheral blood mononuclear cells (PBMCs) with $1,25(\mathrm{OH})_{2} \mathrm{D}_{3}$ in RA patients, the levels of IFN- $\gamma$, TNF- $\alpha$, IL-2, IL-6 and IL-17 significantly decreased compared to those of the control. $1,25(\mathrm{OH})_{2} \mathrm{D}_{3}$ had no significantly impact on the levels of IL-4, IL-10 and IL-22. The levels of Th17 and the ratio of Th17/Treg significantly decreased in $1,25(\mathrm{OH})_{2} \mathrm{D}_{3}$ treated 